\title{
Guatemala. Unterentwicklung und Gewalt
}

Aus dem Spanischen übersetzt von Tilla Siegel und Manfred Trzenschick. Frankfurt am Main 1971 (Edition Suhrkamp, Bd. 457), S. 162, 7,80 DM.

Die erfolgreiche Revolution in Nicaragua gegen die dienstälteste Diktatur Lateinamerikas und die seither auch in Guatemala, El Salvador und Honduras explosive Lage hat den Blick der Weltöffentlichkeit auf eine Region gelenkt, in der sich gleichsam focusartig die politischen und sozialen Gegensätze des Halbkontinents konzentrieren: Schauplatz der ersten erfolgreichen Integrationsbemühungen ebenso wie des neben dem Chaco-Krieg (1932-1935) einzigen Krieges in diesem Jahrhundert, des sogenannten ,FFußballkrieges“ 1969 zwischen El Salvador und Honduras; Heimat der stabilsten Dem.okratie Lateinamerikas (Costa Rica) und zugleich einiger seiner rückständigsten Militärregimes. Aus aktuellem Anlaß erscheint es daher gerechtfertigt, an Alfonsos Monographie zu erinnern, die dem nach Nicaragua zweitgrößten, politisch aber wohl führenden Land des Isthmus gewidmet ist. Der Autor, Soziologieprofessor in Madrid, führt den Leser engagiert und kompetent in die Wirtschafts- und Sozialgeschichte Guatemalas ein. Er schildert die Populations- und Klassenstruktur des Landes, wie sie insbesondere vom Gegensatz zwischen Indios und ,Ladinos“ geprägt ist, ébenso sorgfältig wie die politische Entwicklung dieses Agrarlandes von der Kolonialepoche über die Unabhängigkeit und die Revolution vom 20. Oktober 1944 bis zum Beginn des Guerilla-Kampfes, den der deutsche Leser meist nur mit der Entführung und Ermordung des Botschafters Graf Spreti im Juni 1970 assoziiert. Auch wenn die neuere und neueste Entwicklung seit 1971 nicht mehr berücksichtigt ist, kann Alfonsos Monographie doch jedem empfohlen werden, der allgemein einen Einstieg in die Beschäftigung mit Zentralamerika sucht, einer Region, die von der etablierten Lateinamerika-Forschung bislang eher stiefmütterlich behandelt worden ist.

Karl Hernekamp

Colin Howard

Australia's Constitution.

Penguin Books (Australia). 1978, Kt. 216 S.

Colin Howard/Cheryl Saunders

Cases and Materials on Constitutional Law.

The Law Book Co. Ltd., Sydney/Melbourne/Brisbane/Perth 1979. Ln. LXIII und 420 S.

Colin Howard

Australian Federal Constitutional Law.

2nd Edition 1972 (Nachdruck 1978). The Law Book Co. Ltd., Sydney/Melbourne/Brisbane/Perth. Kt. oder Ln. LX und 535 S.

Der Verfasser des vorstehend zuerst genannten Taschenbuchs ist Dekan der Juristischen Fakultät der University of Melbourne. Er unternimmt es, die australische Verfassung dem nicht juristisch vorgebildeten Bürger, aber auch dem Ausländer, der sich einen ersten Überblick verschaffen möchte, nahezubringen. In leicht verständlicher Sprache werden auch schwierige verfassungsrechtliche Fragen meisterhaft, zuweilen auch kritisch - z. B. hinsicht- 